\title{
EL DEPÓSITO BANCARIO DE DINERO
}

\author{
Erick Manuel Casco Muñoz \\ Instructor del Bufete Jurídico \\ Universidad Centroamericana
}

$\mathrm{E}$

n el presente trabajo se realiza un estudio general de una de las figuras más comunes en la contratación bancaria en el ámbito mundial, me refiero al contrato de depósito de dinero, el cual junto al préstamo dinerario constituye el núcleo fundamental de la actividad de intermediación financiera que las instituciones bancarias llevan a cabo con mayor regularidad, pues precisamente en ello estriba su función principal.

El depósito de dinero, dentro de la clasificación general de las operaciones bancarias -operaciones activas, pasivas y neutras- ${ }^{1}$, es la operación pasiva por excelencia. Es mediante este contrato que los bancos logran obtener la mayoría de los recursos monetarios que posteriormente colocarán entre sus clientes bajo todas las formas contractuales que se agrupan dentro de las operaciones activas. Los bancos no pueden realizar toda su actividad con capital propio únicamente, es por ello que la actividad bancaria se transforma en un «negocio con el dinero ajeno», como señala el economista GUIDE . $A^{2}$.

1 Las operaciones activas son aquellas mediante las cuales las entidades de crédito conceden a sus clientes sumas dinerarias, o disponibilidad para obtenerlas, con cargo a los capitales que han recibido de sus clientes o a sus propios recursos financieros. En el caso de las operaciones bancarias pasivas, nos encontramos frente a aquellas operaciones mediante las que las entidades de crédito reciben medios y disponibilidad monetaria y financiera de sus clientes, para aplicarlas a sus fines propios. Las operaciones neutras son aquellas actividades bancarias, en las que el servicio que se presta no suponen concesiones u obtenciones de crédito. BROSETA PONT, Manuel; Manual de Derecho Mercantil, V. II, 2003, Pág. 222-223.

2 GUIDE A. Curso de Economía Política, página 303, citado por TAGORE SOLNIÊ. Gerardo, en Enciclopedia Jurídica Omeba (Dir. Manuel Osorio y Florit), Vol. VII. Pág. 814, Buenos Aires, 2001. 
El depósito de dinero cobra gran importancia dentro de la actividad bancaria, esa relevancia no se queda, sin embargo, dentro del sector de las entidades de crédito, sino que también tiene efectos sobre la economía nacional, los cuales se traducen a la regulación del total de moneda circularte que permite -dicho sea de paso- controlar el fenómeno de la inflación, y hace posible de igual manera que los sectores productivos puedan tener acceso a determinada cantidad de recursos monetarios necesarios para desarrollarse.

\section{Antecedentes Históricos}

El depósito de dinero es una operación muy antigua, algunos autores encuentran sus antecedentes en Babilonia, Egipto y posteriormente en la antigua Grecia. Los habitantes, confiando en la honestidad de los anfitriones entregaban sus fondos en depósitos a los templos, cuyas autoridades operaban con esos fondos ${ }^{3}$. Posteriormente esta actividad pasó a mano de los trapecistas, quienes captaban dinero en forma de depósito para posteriormente operar con él cobrando intereses.

En la antigua Roma, el depósito llega a tener más trascendencia en la actividad comercial, partiendo de la Fiducia cum amico ${ }^{4}$, derivada de la imposibilidad de transferir la posesión sin el dominio, se llegó a entender al depósito como una figura autónoma atribuyendo al depositario la obligación de custodia y restitución; se establecieron diferencias entre depósito regular e irregular de dinero. Señala el profesor Garrigues, que fueron los romanos los primeros que plantearon la problemática de la naturaleza jurídica de aquel contrato que llevaban a cabo los argentarii (banqueros), que consistía en admitir dinero ajeno en depósito con facultad de uso. El adquirir la propiedad de lo depositado, según el profesor Garrigues, deja abierta la duda de si se trataba en verdad de un contrato de depósito o un contrato de préstamo ${ }^{5}$.

Documentos que datan de la Edad Media, que son estatutos de las ciudades italianas de los siglos XIII y XIV, citan ejemplos de depósitos que realizaban los Estados y los municipios en los banqueros privados, y los que realizaban los Papas en los banqueros sienenses y florentinos. En esta época la recepción de depósitos constituía la diferencia principal entre los banchieri (banqueros), y los capsores (cambistas), durante esta etapa lo frecuente era permitirle al banquero poder disponer de las monedas depositadas hasta que el depositante las requiriese ${ }^{6}$.

3 GRECO. P. Curso de Derecho Romano, Pág. 59, citado por TAGORÉ SOLNIÉ, Gerardo, en Enciclopedia Jurídica Omeba (DIR. Manuel Osorio y Florit), Vol. VII; Pág. 814.

4 Cfr. IGLESIAS, Juan, Derecho Romano; Ariel; Barcelona; 2002, Pág. 220-258.

5 GARRIGUES, Joaquín, Contratos Bancarios, 1975, Pág. 352-353.

6 Ídem. 
Algunos sostienen, que los depósitos se usaron en la Edad Media para sanear la circulación fiduciaria; esto sucedía porque se presentaban con frecuencia fraudes contra la moneda, por tanto el comerciante que llevaba a cabo operaciones de comercio en el ámbito internacional o interestatal, depositaba su dinero en una entidad bancaria, la que le acreditaba unidades de moneda de cuenta en función del valor intrínseco de la moneda entregada y, con igual base, pagaba a los acreedores del comerciante ${ }^{7}$.

Es a partir del siglo XIX que el depósito de dinero adquiere la forma que actualmente conserva, situación que se produce por el aumento de las necesidades de pago como consecuencia del incremento de la actividad industrial y de las transacciones mercantiles. En el momento en el que el banco se da cuenta de que las operaciones de depósito y retiro le permiten aplicar la ley de los grandes números, comprende que la paralización del patrimonio bajo su custodia no es necesaria sino en una mínima proporción, dado que durante la mayoría del tiempo podrá restituir a los depositantes que lo requieran los montos correspondientes, con sólo la utilización de la décima parte del dinero depositado, es en este momento que comienza a operar con el restante saldo libre a través de los créditos. A partir de entonses, el depósito de dinero adquirió la trascendencia que actualmente tiene ${ }^{8}$.

\section{Concepto}

El depósito es una figura contractual regulada tanto por legislación civil, como la mercantil y la bancaria de nuestro país, en cada una de ellas este contrato presenta matices particulares en cuanto que las cosas a ser depositadas no necesariamente serán siempre dinero" y el grado de disponibilidad para hacer uso de él que tenga el depositario.

Así pues el contrato de depósito bancario de dinero, que es el tema a desarrollar en este pequeño artículo, se puede definir como, «El contrato en virtud del cual el depositante (cliente del banco), entrega a un banco una determinada suma de dinero de la que éste pasa a ser titular y de la que por tanto puede disponer pero que en

7 TAGORÉ SOLNIÉ, Gerardo, en: Enciclopedia Jurídica Omeba (Dir. MANUEL OSORIO Y FLORIT), Vol VII; 2001, Pág. 815.

8 Ídem.

9 Nuestro Código Civil, usa el término cosa en sentido genérico, para hacer referencia a los objetos que pueden ser depositados (Art. 3449 C). El Código de Comer cio señala que pueden ser depositadas bajo el régimen del depósito mercantil las cosas objeto de comercio o el depósito que se haga en virtud de una operación mercantil. En el caso de nuestra Ley General de Bancos, es deducible que las entidades bancarias recibirán en concepto de depósitos básicamente, dinero y títulos valores. 
todo caso ha de custodiar, con el compromiso de devolver una suma igual a la recibida en la moneda, tiempo y forma pactada.» ${ }^{10}$ Cuando no se haya definido plazo para la devolución de la cantidad de dinero depositado, el depositario devolverá al depositante cuando este le requiera la cantidad correspondiente.

Este concepto brinda elementos muy importantes a tener en cuenta, y que merecen ser analizados:

El depósito de dinero en un banco se ubica dentro de los depósitos irregulares ${ }^{11}$, en vista de que la actividad bancaria se centra en la administración de recursos monetarios y dentro de esa actividad el depósito de dinero adquiere una gran relevancia, dado que le permite al banco captar gran cantidad de recursos del público, los cuales podrá utilizar luego, y porque estamos frente a un bien fungible, como lo es el dinero, y además porque en los depósitos irregulares el titular del bien depositado no es ya el depositante sino el depositario, es posible que el banco haga uso del dinero que percibe en tal concepto. Por tanto es posible afirmar que en los depósitos bancarios de dinero estamos frente a un depósito irregular de dinero.

En la definición que de contrato de depósito se daba, se señala que el banco pasa a ser titular del dinero en él depositado, por tanto aquella idea de que el dinero

10 VALENZUELA GARACH, Fernando; (JIMÉNEZ SÁNCHEZ-Director), Derecho Mercantil, tomo II, 2000, Pág. 468

11 Existen dos modalidades de depósitos establecidas, el depósito regular que es el contrato por medio del cual, una persona entrega una cosa mueble a otra, para que esta la conserve en su poder y la restituya cuando el depositante así lo requiera. En esta modalidad la obligación principal del depositario consiste en conservar y custodiar la cosa que ha recibido y devolverla al depositante cuando este la requiera (esta es la modalidad de depósito que nuestro código civil regula, pues entiende que cuando se transfiera la potestad de usar lo depositado se está frente a un mutuo, comodato, uso, o usufructo), el depositario no podrá hacer uso de la cosa, no podrá consumirlo ni disponer del mismo; se entiende entonces que lo depositado bajo la modalidad de depósito regular no será un bien fungible o consumible. Frente a la situación de encontrarse con el depćcito de un bien fungible o consumible, la doctrina y algunas legislaciones, como el caso de la mexicana y la española, entendieron que era valedera la posibilidad de mantener el esquema del depósito, sustituyendo la obligación principal del depositario, de devolver el mismo bien por una obligación de género consistente en devolver en una porción o totalmente bienes de la misma calidad y especie. Así pues surge la calificación del depósito irregular, el cual se caracteriza por el hecho de que el depositario adquiere la propiedad de los bienes que recibe y puede disponer libremente de ello en cuanto su obligación se reduce a devolver una cantidad equivalente. RODRÍGUEZ AZUERO, Sergio, Contratos Bancarios, 1997, Pág. 134-135. Cfr. GARRIGUES, Joaquín; Curso de Derecho Mercantil, (Revisada con la Colaboración de FERNANDO SÁNCHEZ CALERO); Tomo II; 6 a Edición; Tecnos, Madrid, 1975, Pág. 134, 135. 
que yo deposité en el banco sigue siendo de mi dominio, no es correcta en cuanto que al momento de realizar el depósito se realizó una traslación de la titularidad de mi dinero al banco (pues estamos frente a un depósito irregular) ${ }^{12}$; lo que existe a favor de su titular es un derecho de crédito, no simultáneo, sino de acuerdo a lo pactado, que le permite hacer efectivo su requerimiento al momento de solicitarle al banco el reembolso de lo depositado ya sea total o parcialmente ${ }^{13}$.

El depositante se convierte, por tanto, en un acreedor del banco, en cuanto tiene para sí un derecho de crédito que le respalda: la recuperación de la suma depositada. JOSÉ LUIS GARCÍA- PITA Y LASTRES, señala que como la fuente principal de recursos de los bancos, para llevar a cabo sus operaciones activas proviene de fondos reembolsables, ello implica una masificación de depósitos bancarios de efectivo, lo que se traduce en un mega endeudamiento funcional planificado, y parafraseando al profesor GARRIGLIES y al profesor FERNANDO SÁNCHEZ CALERO, "El banco, en esencia, vive en una condición masiva y crónica de deudor» ${ }^{14}$.

Como se ha expresado anteriormente, el banco adquiere la titularidad de las sumas dinerarias depositadas, y es por esa transmisión de dominio que el banco queda facultado a disponer del dinero depositado ${ }^{15}$, no obstante el deber de custodia que está presente en la figura del depósito regular, no deben ser entendido en sentido estricto para el caso del depósito irregular, precisamente por esa transmisión de dominio que se produce: se entiende que lo que el banco tiene

12 Ya el Profesor GARRIGUES, sostenía que: «la expresión propiedad del dinero tiene quizá tan sólo un valor teórico, pues la mayor parte de lo que llamamos nuestro dinero está depositado en un banco y, en realidad ha dejado de ser nuestro para pasar a ser del banco. Este paso de propiedad es lo que caracteriza precisamente al llamado depósito irregular». GARRIGUES, Op. Cit.; Pág. 354,35; nota 6.

13 En las operaciones pasivas, los bancos reciben créditos porque la parte que entrega las sumas dinerarias al banco obtiene el derecho de crédito a exigir la restitución de lo entregado. BROSETA PONT, Op. Cit. Pág. 223

14 GARCÍA - PITAy LASTRE, José Luis,(UBALDO NIETO CAROL-coordinador), Contratos bancarios \& Parabancarios, 1998, Pág. 899. No hay que olvidar, que frente a esa condición de deudor que ostenta el banco, se contrapone su condición de acreedor, por todos aquellos créditos que otorga, lo que también le hace estar en una privilegiada posición, por todos los privilegios con que cuenta.

15 GARCIA-PITA y LASTRE, Op. Cit., Pág. 902-903. La transmisión de la titularidad del dinero depositado está lejos de ser un elemento circunstancial del contrato, es un elemento esencial del mismo pues es de ésta manera como se explica la realización de la actividad de intermediación financiera que ejercen los bancos. CORTEZ, Luis Javier, (URÍA-MENENDEZ-Coord.), Curso de Derecho Mercantil, 2001, Pág. 539. Hay quienes entienden en el medio académico nuestro, que la utilización de los recursos depositados por los clientes en los bancos, obedece a una costumbre pero que en ningún momento se está frente a un depósito, mucho menos a la transmisión de la titularidad. 
para con el depositante es una obligación de disponibilidad ${ }^{16}$, que viene a sustituir el deber de custodia que existe en el depósito regular ${ }^{17}$.

El derecho de crédito que el depositante tiene a su favor, será ejercido de acuerdo a las condiciones en las que se contrató, puesto que no se podrá por ejemplo el caso de los depósitos a plazo fijo retirar cuando el depośitante así lo quiera, tiene que sujetarse a una serie de condiciones contractuales que le impiden actuar de esa forma, no así en el caso de los depósitos a la vista, de los que se hablará más adelante.

Independientemente de la denominación contractual que se dé a este tipo de contratos en la práctica, dado que por lo general las personas entienden que es una actividad de ahorro lo que se estállevando a cabo y se contrata bajo la denominación de cuenta de ahorro, considero que se está frente a un depósito irregular, independientemente de cómo quiera llamarle la entidad financiera.

\section{Función Económica del Depósito Bancario de Dinero}

La función económica del depósito bancario de dinero debe ser vista desde ángulos o perspectivas diferentes, en cuanto que la importancia que el depósito puede tener para el depositante, no es la misma que para el depositario (Banco); a su vez entre los depositantes los intereses pueden variar según se trate de un empresario o de un particular.

El interés general que mueve a las personas a realizar depósitos en los bancos es el de obtener custodia de sus recursos monetarios en una entidad que garantiza un determinado grado de seguridad, obtener un servicio de caja que en determinados casos permita realizar pagos y obviamente, un determinado grado de

16 La disponibilidad debe ser entendida de acuerdo a GARCÍA-PITA Y LASTRE, como un sustituto de la obligación de custodia, incluyendo o no un conjunto de comportamiento y actividades económico / financieras tendentes a hacer posible que se pueda efectuar la restitución. Esta obligación de disponibilidad será garantizada a través de una serie de normas administrativas coactivas, que el Estado a través del ente regulador dispone. MARTÍNEZ SANZ, en el Manual de Derecho Mercantil del Profesor BROSETA PONT, afirma: «En efecto, el banco no está obligado a guardar(custodiar), el bien depositado, convirtiéndose el deber de custodia propio del deposito mas bien en una obligación de disponibilidad lograda a través de una inversión prudente de los fondos depositados y una correcta administración de recursos propios y ajenos...». BROSETA PONT, Op. Cit., Pág. 248.

17 Afirma el Profesor GARRIGUES al tratar la naturaleza jurídica del depósito bancario de dinero, que en el depósito bancario de dinero el deber de custodia se esfuma siendo sustituido por el elemento de la disponibilidad a favor del cliente. GARRIGUES, Contratos... Op. Cit.; Pág. 364, 365. 
utilidades por las sumas que en concepto de interés los bancos acreditan a sus clientes depositantes.

Para GERARDO TAGORÉ SOLNIÉ, la función económica del depósito es muy importante en cuanto que el importe de lo ahorrado por el público, se reinvierte en forma de préstamos o descuentos. No obstante el mismo autor, citando a KEYNES, señala que los recursos que se captan en concepto de depósito deben de ser proporcional al total de inversiones que deben ir a los sectores que más lo necesiten, sin embargo, en un sistema económico liberal, la forma de disposición de los recursos depende de los actores del medio, es decir, de quienes tienen los recursos suficientes para tenerlos en el banco y de las entidades de crédito, al decidir éstas a qué sectores sociales dirigir los créditos ${ }^{18}$.

La importancia económica que el depósito bancario de dinero puede tener para una persona puede ser explicado de la siguiente manera: cada persona tiene en su poder una determinada cantidad de dinero de la cual es propietaria, ese derecho real que se ostenta sobre esos bienes fungibles que son los billetes y monedas con un determinado valor monetario es definitivamente más fuerte que un derecho de crédito y más inmediato, en cuanto que se puede disponer de la cantidad que se requiera sin limitación alguna, no obstante, el riesgo económico y jurídico que está presente por la pérdida económica o destrucción de esos bienes es asumido por el propietario.

Es precisamente el riesgo antes mencionado el que el depositario pretende eludir, lo cual logra entregando al banco la sumas dinerarias de las cuales es propietario. Al banco le transfiere la titularidad de las mismas, por tanto ese derecho real absoluto que tenía sobre el dinero es sustituido por el derecho de crédito. Aunado a ello, el riesgo del que se hablaba anteriormente se vuelve casi nulo para el depositante, ya que al asumir el banco depositario la titularidad de las sumas dinerarias, ese riesgo le ha sido trasladado.

Para el banco, la trascendencia económica que el depósito de dinero puede tener, está determinada por las características económicas y jurídicas que el dinero posee: constituye el principal instrumento de acumulación de riquezas y adquisición de bienes y servicios. Quienes no lo poseen para realizar este tipo de actividades o no lo poseen en cantidad suficiente, requieren de alguien que esté dispuesto a facilitárselos, invirtiéndolo. Los bancos que cuentan con esos recursos provenientes de los depósitos los canalizan hacia la inversión.

18 TAGORÉ SOLNIÉ, Op. Cit., Pág. 815. 


\section{Naturalleza Jurídica}

La naturaleza jurídica del depósito bancario de dinero es un tema dentro de este contrato en el que la mayoría de los autores partiendo de GARRIGUES, han entendido que se está frente a un depósito irregular; la irregularidad es según el Profesor GARRIGUIES, "La exclusión o modificación de un elemento no esencial, pero sí característico del contrato, es decir, de aquellos que deben ser sobreentendidos en la figura normal del pacto.» ${ }^{19}$. En el depósito regular el depositante continúa siendo propietario del bien depositado, en el depósito irregular, el depositario adquiera la propiedad del bien depositado y puede consumirlas devolviendo al final una cosa de igual especie y calidad ${ }^{20}$.

Ni nuestro Código civil ni el Código de Comercio regulan la figura del depósito irregular, ambos cuerpos legales reconocen sólo la figura del depósito regular, no obstante el que no esté normado el depósito irregular en nuestra legislación no significa que no sea aplicable, existe una clara posición de la doctrina respecto de la existencia de esta modalidad de depósito y su aplicación es innegable en el actuar diario de las instituciones bancarias.

Independientemente de la figura contractual bajo la cual se designen estos contratos que por lo general se innominan como cuentas de ahorro, es claro que estamos frente a un contrato de depósito y así lo establece la Ley General de Bancos (Art. 40 - 44). En estos artículos no se hace referencia a la transmisión del dominio del dinero depositado, sí se establece en el articulo 42, que los bancos podrán invertir los fondos disponibles provenientes de los depósitos, esa posibilidad de disponer de los recursos está dada por un transmisión de la titularidad operada a través del depósito.

La facultad de disposición del dinero depositado en el banco viene dada por esa transmisión de la titularidad que hemos venido recalcando es fruto del depósito irregular. Es por ello que considero al igual que la mayoría de la doctrina que la naturaleza jurídica del depósito bancario de dinero se halla en el depósito irregular.

En los casos de los depósitos a plazo, algunos consideran que la naturaleza jurídica de este tipo de depósitos es la de un préstamo ${ }^{21}$, ( traspaso de la propiedad y restitución en un determinado plazo de las sumas recibidas), no obstante, GARRIGUES afirma que no

19 GARRIGUES, Op. Cit., Pág. 361, nota 17.

20 El profesor Garrigues recalca en la nota antes citada, que el depósito irregular, la naturaleza fungible de la cosa depositada (cuando se entrega cosa fungible, siendo obviamente el dinero uno de los bienes que caben dentro de esta clasificación), no admite la coexistencia de un derecho de propiedad del depositante, y un derecho de consumo del depositario. Este último se hace propietario de la cosa y soporta como tal sus riesgos.

21 GARRIGUES, Op. Cit., Pág. 377. 
es ni préstamo ni depósito, aunque se siga llamando depósito; lo ubica dentro de un contrato sui generis.

Para otros autores como GARCÍA-PITA Y LASTRE22, no es ni Mutuo ni contrato sui generis, estamos siempre frente al contrato de depósito irregular, porque habrá una transmisión de la titularidad y se trasladarán los riesgos propios de la titularidad de dinero.

Esta última consideración es la que en este trabajo se apoya. Los depositantes no acuden a las entidades bancarias con el ánimo de conceder préstamos a los bancos, ni los bancos actuarían con esa finalidad.

\section{Clasificación de los Depósitos Bancarios}

Los depósitos bancarios se clasifican generalmente en: depósitos a la vista, a plazo y de ahorro ${ }^{23}$, esta clasificación brindada desde el punto de vista jurídico toma como referencia el momento en que se puede ejercitar el derecho de crédito que trae consigo el depósito bancario de dinero.

En el caso de los depósitos a la vista, estamos frente a aquellos depósitos en los que la entidad de crédito está obligada a devolver las sumas depositadas en el momento mismo en que el depositante así lo pida ${ }^{24}$. El clásico depósito a la vista es el depósito en cuenta corriente, mediante esta modalidad, se permite que el depositante pueda aumentar o disminuir mediante sucesivos actos de ingresos o retiros, las sumas depositadas, todo ello de acuerdo a lo pactado en el contrato. El contrato que rige esta modalidad de depósito es por lo general por tiempo indefinido y tácitamente renovable, da lugar a liquidaciones periódicas de intereses, se facilita a cada cliente una libreta, cuya naturaleza es un simple título de legitimación ${ }^{25}$.

Este tipo de depósitos, dado el desarrollo de los servicios prestados por un ban$\mathrm{co}$, se ven matizados por una serie de operaciones que el mismo banco se obliga a brindar (el servicio de caja, cheques transferencias, etc.), dirigidas a incrementar el depósito. La amplia difusión de esta modalidad ha permitido que se haya ido afirmando la propia sustantividad de esta modalidad de depósito bajo la

22 GARCIA-PITA y LASTRE, Op. Cit., Pág. 979 y ss.

23 El artículo 40 de la Ley general de Bancos recoge esta misma clasificación al señalar: "Los depósitos podrán constituirse en calidad de a la vista, de ahorro o a plazo»

24 CORTES, Luis Javier, en URÍA-MENENDEZ, Op. Cit.., Pág. 540.

25 De acuerdo a Luis Javier Cortés, es esta situación la que explica que en la práctica sea conocida como libreta o cuenta de ahorro a la vista. CORTEZ, Luis Javier, en URÍA MENÉNDEZ, Op. Cit., Tomo II, Pág. 540. JIMENEZ SANCHEZ, Guillermo, Derecho Mercantil, Tomo II, Pág. 
denominación de cuenta corriente bancaria; respecto de ella el depósito pasa a ser tan sólo un antecedente o presupuesto que proporciona la provisión o disponibilidad de fondos que exige su funcionamiento ${ }^{26}$.

En contraposición a los depósitos a la vista está el depósito a plazo fijo ${ }^{27}$. En un primer momento, esta modalidad de depósito no parece presentar ninguna diferencia con el depósito a la vista (en cuanto a la restitución), ya que el banco está obligado a restituir en el momento oportuno lo depositado más los intereses correspondientes. El documento que acredita este tipo de depósito es el certificado de depósito, el que es posible considerar un título valor, por tanto transmisible mediante endoso o por cualquier otro mecanismo admitido por el Derecho ${ }^{28}$.

Los elementos que llevan a entender que estamos frente a un título valor son los siguientes: a) se emiten a la orden y por consiguiente son transmisibles mediante endoso, b) los rasgos económico jurídicos determinan que el certificado de depósito a plazo sea un documento con vocación esencialmente circulatoria; c) son títulos que cumplen una función probatoria como resguardo acreditativo de la recepción de una determinada suma de efectivo, en concepto de depósito a plazo, lo que hace al certificado de depósito un título eminentemente causal; d) es un documento que tiende a facilitar los actos de disposición sobre un crédito cuya vida es relativamente prolongada ${ }^{29}$.

De igual manera es necesario tomar en cuenta, que para que el certificado a plazo fijo sea considerado un título valor, debe contener ciertos elementos propios de estos documentos como son la abstracción, que implica una total independencia del titulo del contrato o causa que le dio origen. La literalidad que implica que el título debe contener la extensión total de los derechos que en él se contengan. Que exista una conexión íntima entre el crédito y el título (principio de incorporación del derecho al documento). El certificado de depósito debe, al ser transmitido, constituir un derecho propio y autónomo a favor del nuevo poseedor ${ }^{30}$.

26 CORTEZ, Luis Javier, en URÍA -MENENDEZ, Tomo II, Op. Cit., Pág. 540-541

27 La naturaleza jurídica de esta modalidad de depósito a la que ya hicimos alusión, es mantenida por FERNANDO VALENZUELA GARACH, en la Obra dirigida por GUILLERMO J. JIMÉNEZ, al entender que se trata de un contrato sui generis, y no que la naturaleza jurídica de este se haya en el préstamo como algunos autores consideran; aunque bien no se puede obviar que se presentan algunas características en el depósito a plazo fijo que se presentan en el préstamo, como es esa obligación básica de restituir la suma depositada junto con el abono de los intereses correspondientes.

28 JIMÉNEZ SÁNCHEZ, Op. Cit,. Pág. 475.

29 GARCIA-PITA Y LASTRE Op. Cit., Pág. 986

30 SOLÓRZANO BELLI, Gonzalo, Titulos Valores, Managua,1997; Pág. 5-7. 
Aunada a la obligación de restitución, se presenta la obligación de respetar el plazo que afecta tanto al depositante como a la institución bancaria, ese hecho, de acuerdo con GARCÍA- PITA Y LASTRE no convierte al depósito en un contrato de préstamo ${ }^{31}$.

Existe también la modalidad de depósito de ahorro, que nuestra legislación regula. En el caso de esta modalidad estamos frente a la siguiente situación:

El depósito de ahorro es la cuenta de ahorro típica, conforme a la cual las personas depositan en el banco sus excedentes monetarios para obtener, en alguna medida, un determinado lucro por los intereses que el banco pagará, no obstante, considero que este tipo de actos no se puede ver como una inversión como tal, dado que quienes contratan bajo esta modalidad son sectores sociales con una disponibilidad de dinero baja, depositan en el banco el monto de dinero que tienen disponible, para realizar una actividad determinada en un momento determinado, pero no con el ánimo de que ese depósito les represente una gran rentabilidad ${ }^{32}$.

Las características de esta modalidad de depósito son las siguientes ${ }^{33}$ :

1. Es depósito irregular.

2. Es en efectivo o en documentos cobrables a la vista

3. Es retirable previo aviso, de acuerdo a normas determinadas.

Los depósitos de ahorro de acuerdo a la Ley general de Bancos nicaragüense ganarán intereses capitalizables, tanto los depósitos como los retiros se llevarán a cabo a través de los documentos que para tal efecto cada institución bancaria entregue a sus clientes, en este sentido, la libreta de ahorro que cada ahorrante recibe del banco, se convierte en un documento de legitimación, para al menos, hacer retiros, dado que los depósitos pueden ser realizados por cualquier persona sin necesidad de presentar tal libreta.

31 GARCIA-PITA Y LASTRE, Op. Cit., Pág. 983.

32 En opinión de SALDAÑA ÁLVAREZ, los depósitos de ahorro constituyen una de las más importantes fuentes de recursos de las instituciones bancarias y es una forma de depósito ideada con el fin de fomentar el hábito de ahorro entre los sectores populares. SALDAÑA ALVAREZ, citado por DÁVALOS MEJIA, en Derecho bancario y Contratos de Crédito, México DF, 1992, Pág. 764

33 DÁVALOS MEJIA, Felipe, Op. Cit., Pág. 763 


\section{Contenido del Contrato de Depósito}

El contrato de depósito bancario de dinero presenta dos características esenciales: es un contrato real y unilateral.

Es un contrato real pues se perfecciona con la entrega de la cosa, en este caso será el dinero que se deposite en el banco; esta es la posición asumida por el profesor Garrigues. El carácter real del depósito bancario de dinero se puede fundamentar en lo señalado por nuestro Código de Comercio, al referir éste que se estará frente a un depósito mercantil si se lleva a cabo en virtud de una operación mercantil ${ }^{34}$, también señala el mismo cuerpo legal, que el depósito se constituirá mediante la entrega al depositario de la cosa que constituye su objeto ${ }^{35}$, reafirmando esta disposición el carácter real que tiene el contrato de depósito.

Las obligaciones en este contrato nacen para el banco, no para el depositario, es este elemento, característico de los contratos reales, ya que sobre el depositante no pesa obligación alguna, en cambio el banco está obligado a restituir el dinero (en virtud del derecho de crédito que el depositante tiene a su favor) y a pagar los intereses debidos al depositante. La obligación de custodia de la que habla el Código civil como ya hemos dicho, desaparece en el depósito bancario de dinero y es sustituida por un deber de disponibilidad.

En cuanto a la unilateralidad, es claro que de este contrato nacen obligaciones solamente para una de las partes: el banco, quien está obligado a tener disponibilidad de recursos para responder a las exigencias del depositante al momento de hacer efectivo su derecho de crédito que vendría a ser la obligación principal, es decir la restitución del monto de dinero requerido al depositante en el momento en que éste lo solicite.

\section{Extinción del Contrato}

Nuestra ley general de bancos, no prevé ninguna de las formas de finalización de este contrato, tampoco e. Código de Comercio, por tanto las formas de extinción de este contrato de depósito bancario de dinero a la vista, en nuestro ordenamiento son los siguientes: el contrato se extingue por el retiro total de lo depositado, lo cual puede verificarse en el momento en que el depositante lo requiera.

34 Art. 460 Código de Comercio. No cabe ni la misma mínima duda de que las operaciones llevadas a cabo por los bancos son operaciones mercantiles, en tanto y en cuanto estos se constituyen como sociedades anónimas y actúan en el tráfico mercantil dentro del giro de su negocio.

35 Art. 462 Código de Comercio. 
En el caso de los depósitos a plazo fijo, el contrato se extingue cuando el tiempo de duración del mismo llegue a su término, las entidades bancarias por lo general al contratar establecen cláusulas que indican que si no se solicita la finalización del contrato este se renueva automáticamente.

La muerte del depositante es otra de las formas de extinción, situación ante la cual el banco entregará lo depositado al beneficiario de la suma depositada en la casa bancaria.

Estas son las reglas básicas de extinción del contrato de depósito bancario de dinero en el régimen jurídico nicaragüense. Las prácticas bancarias rigen estas forma de extinción frente a la falta de un régimen legal existente en nuestra legislación, dejando por tanto un campo bien amplio en esta materia a la autonomía de voluntad de las partes, expresada a través de condiciones generales de contratación.

\section{BIBLIOGRAFIA}

- AAVV, "Contratos Bancarios \& Parabancarios", (Ubaldo Nieto Coordinador), Lex Nova, Valladolid, 1998.

- BROSETA PONT, Manuel, "Manual de Derecho Mercantil", Edición actualizada por Fernando Martínez Sanz, Tomo II, 11ª Edición, Tecnos, Madrid, 2003.

- CORTEZ, Luis Javier, Curso de Derecho Mercantil, (URÍA-MENENDEZCoord.), Vol. II, Civitas, Madrid, 2001.

- DÁvAlOS MEJIA, Carlos Felipe, "Derecho Bancario y Contratos de Crédito",2 2 Edición, Oxford, México D.F, 2000.

- GARRIGUES, Joaquín, "Contratos Bancarios", 2a , Edición, Tecnos, Madrid, 1975.

- GARRIGUES, Joaquín; Curso de Derecho Mercantil, (Revisada con la Colaboración de FERNANDO SÁNCHEZ CALERO); Tomo II; $6^{a}$ Edición; Tecnos, Madrid, 1975.

- IGLESIAS, Juan;Derecho Romano(Revisado con la Colaboración de JUAN IGLESIAS-RENDON), 14ª Edición; Ariel; Barcelona; 2002. 
- RODRÍGUEZ AZUERO, Sergio, "Contratos Bancarios", 4" edición, FELABAN, Bogotá, 1997.

- SANCHEZ CALERO, Fernando; Instituciones de Derecho Mercantil; Vol. II, 14: Edición;

- Mc-Graw Hill; Madrid, 2002

- SOLORZANO BELLI, Gonzalo, "Títulos Valores", Editorial UCA, Managua 1997.

- SOLORZANO REÑAZCO, Aníbal, "Glosas al Código de Comercio", 3" Edición, HISPAMER, Managua, 1999.

- TAGORÉ SOLNIÉ, Gerardo, en Enciclopedia Jurídica Omeba (Dir. Manuel Osorio y Florit), Vol. VII, Omeba, Buenos Aires, 2001.

- VALENZUELA GARACH, Fernando, "Derecho Mercantil" (Guillermo J. Jiménez Coordinador), Tomo II, 6 a Edición Corregida y Puesta al día, Ariel, Barcelona, 2000. 